\title{
Regulatory mechanism underlying cyclic changes in mouse uterine bicarbonate secretion: role of estrogen
}

\author{
Qiong He ${ }^{1}$, Hui Chen ${ }^{1}$, Connie Hau Yan Wong ${ }^{1}$, Lai Ling Tsang ${ }^{1}$ and Hsiao Chang Chan ${ }^{1,2}$ \\ ${ }^{1}$ Epithelial Cell Biology Research Center, School of Biomedical Sciences, Faculty of Medicine, The Chinese University \\ of Hong Kong, Shatin, NT, Hong Kong, People's Republic of China and ${ }^{2}$ Joint Laboratory of Reproductive Medicine, \\ SCU-CUHK, Institute of Women and Children's Health, West China Second University Hospital, Sichuan University, \\ Chengdu 610041, People's Republic of China
}

Correspondence should be addressed to H C Chan at Epithelial Cell Biology Research Center, School of Biomedical Sciences, Faculty of Medicine, The Chinese University of Hong Kong; Email: hsiaocchan@cuhk.edu.hk

\begin{abstract}
Our previous study has demonstrated that bicarbonate in the uterine fluid plays an indispensable role in sperm capacitation. However, the cellular mechanisms underlying the formation of bicarbonate-rich uterine fluid and the regulatory mechanism remained largely unknown. In this study, the expression profiles of bicarbonate transport/production proteins, the cystic fibrosis transmembrane conductance regulator (CFTR), SLC26A6, carbonic anhydrase 2 (CAR2, CA2) and CAR12 (CA12), throughout the estrous cycle, were examined in the mouse uterus by western blot. The results showed that the maximum expression levels of the proteins examined were observed at estrus. Luminal surface $\mathrm{pH}$ measurements showed that the resting uterine surface $\mathrm{pH}$ at estrus was significantly higher than that at diestrus, which could be reduced significantly by CFTR blocker, diphenylamine-2,2' -dicarboxylic acid, SLC26A6 inhibitor, $4^{\prime}, 4^{\prime}$-diisothiocyanostilbene-2' $2^{\prime}$-disulfonic acid, and CA inhibitor, acetazolamide. In ovariectomized mice and primary culture of endometrial epithelial cells, estrogen could upregulate CFTR, SLC26A6, CAR2, and CAR12 expression with a corresponding increase in the bicarbonate-dependent short-circuit current $\left(I_{\mathrm{sc}}\right)$ and endometrial surface $\mathrm{pH}$. The present results have demonstrated dynamic changes in uterine bicarbonate secretion and expression of the proteins involved in bicarbonate secretion during the estrous cycle and suggested a novel role of estrogen in regulating uterine bicarbonate transport, which may be important for successful reproduction. Reproduction (2010) 140 903-910
\end{abstract}

\section{Introduction}

The fluid environment in the female reproductive tract is considered of physiological significance for a number of reproductive events, including sperm transport and capacitation, fertilization, embryo transport, development, and blastocyst implantation (Aitken 1979, Chan et al. 2002). Disturbance of the fluid microenvironment in pathological conditions, such as cystic fibrosis (Kopito et al. 1973) or hydrosalpinx (Mukherjee et al. 1996), is known to result in infertility. Cyclic changes in the uterine fluid volume and composition were observed 80 years ago (Evans \& Long 1922). It has been proposed that higher uterine fluid production facilitates sperm transport at estrus, and reduced fluid volume at metestrus or diestrus enables closure of the uterine lumen for embryo implantation. The molecular basis for the cyclic changes in uterine fluid volume has been provided by the observed cyclic changes in the expression of uterine cystic fibrosis transmembrane conductance regulator (CFTR), a cAMP-dependent anion channel known to provide the driving force for transepithelial fluid secretion, during the estrous cycle (Chan et al. 2002). The high expression level of CFTR correlates with the maximum uterine fluid volume at proestrus/estrus and the low expression level of CFTR with the minimum uterine fluid volume at metestrus/diestrus, and these correlate with levels of estrogen and progesterone as well as estrogen and progesterone effects on regulation of CFTR expression (Rochwerger \& Buchwald 1993, Rochwerger et al. 1994, Mularoni et al. 1995). Obviously, the ovarian hormones play an important role in regulating the uterine fluid volume; however, their role in regulating the composition of the uterine fluid, i.e. the secretion of particular ions, has not been elucidated.

It was recognized more than 40 years ago that uterine fluids contain two- to four-fold higher bicarbonate content than plasma (Vishwakarma 1962, Murdoch \& White 1968). Accumulating evidence indicates a major role of bicarbonate in a series of reproductive processes such as sperm motility, hyperactivation, capacitation, and acrosome reaction as well as embryo development and differentiation 
(Kane 1975, Lee \& Storey 1986, Visconti et al. 1999, Suarez \& Ho 2003). However, the molecular mechanisms underlying the formation of bicarbonaterich fluid in the female tract and its regulation remain largely unknown. A recent study in our laboratory has demonstrated that the secretion of bicarbonate through the apical membrane of the endometrial luminal epithelium is mediated by CFTR and $\mathrm{a} \mathrm{Cl}^{-} / \mathrm{HCO}_{3}^{-}$ exchanger (Wang et al. 2003), the identity of which is unknown but is likely to be a member of SLC26A6 (Markovich 2001). Our previous studies have also shown that bicarbonate can be accumulated in endometrial epithelial cells either by a $\mathrm{Na}^{+}-\mathrm{HCO}_{3}^{-}$co-transporter (Wang et al. 2002) across the basolateral membrane or by production through intracellular $\mathrm{CO}_{2}$ hydration catalyzed by the carbonic anhydrases (CAs; Sterling \& Casey 2002). Although mounting evidence suggests the importance of bicarbonate in regulating sperm function in the female reproductive tract, the expression profile of bicarbonate transport/production proteins, except CFTR, during estrus cycle and possible involvement of ovarian hormones in regulating their expression have not been reported.

In this study, we hypothesize that bicarbonate transport/production proteins, CFTR, SLC26A6, and CAs are involved in the endometrial epithelial bicarbonate transport, are dynamically changed by the estrous cycle, and may be important for successful fertilization. The aim of this study was to investigate the expression profile of CFTR, SLC26A6, and two CA isoforms known to be expressed in the endometrium, CAR2 (CA2) and CAR12 (CA12) (Sterling \& Casey 2002), in mouse uterus at different stages of the estrous cycle by western blot analysis. The functional role of the proteins in the uterine bicarbonate secretion was further confirmed by the short-circuit current $\left(I_{\mathrm{sc}}\right)$ technique and luminal surface $\mathrm{pH}$ measurement. The possible involvement of estrogen in regulating the expression of these proteins was studied in ovariectomized (OVX) mice with exogenously administered estrogen and specific antagonist of its receptor.

\section{Results}

\section{Expression profiles of bicarbonate transport/production proteins during the estrus cycle}

The expression of the bicarbonate transport/production proteins during the estrous cycle was examined by western blot with $\beta$-tubulin as the loading control (Fig. 1). There were two bands detected for CFTR, with the upper band being the mature, glycosylated form at $180 \mathrm{kDa}$, which was only expressed at estrus, and the lower band being the immature, core-glycosylated precursor, which was expressed in other stages of the estrous cycle. The expression of SLC26A6, detected as two bands at 80 and $85 \mathrm{kDa}$, was the highest at estrus compared with those observed at other stages during the
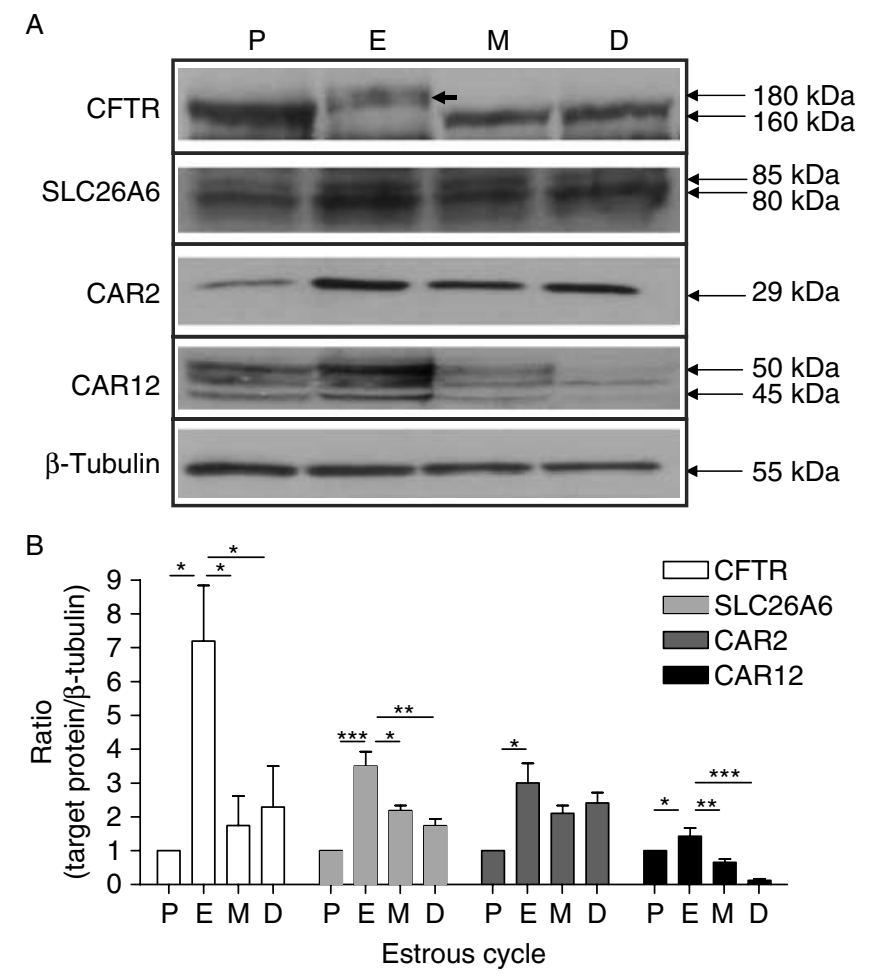

Figure 1 Western blotting analysis of total homogenate from mouse uteri for CFTR, SLC26A6, CAR2, and CAR12 throughout the estrous cycle. (A) Representative photos of western blot analysis. P (Proestrus), $\mathrm{E}$ (Estrus), $\mathrm{M}$ (Metestrus), and D (Diestrus). $\beta$-Tubulin was used as a loading control. The expression levels of the bicarbonate transport/ production proteins are higher at estrus than that of other stages. (B) Quantitation of the western blot analysis of CFTR, SLC26A6, CAR2, and CAR12 expression throughout the estrus cycle $(n=3$ for each group, ${ }^{*} P<0.05,{ }^{* *} P<0.01$, and $\left.{ }^{* * *} P<0.001\right)$.

estrous cycle. The same pattern was observed for CAR2 expression, detected at $29 \mathrm{kDa}$, with the maximum level at estrus. Maximal expression level of CAR12, with two bands at 45 and $50 \mathrm{kDa}$, was also observed at estrus.

\section{Uterine luminal surface $\mathrm{pH}$ during the estrous cycle}

We then examined whether the cyclic expression patterns of the bicarbonate transport/production proteins correlate with variations in uterine luminal $\mathrm{pH}$ at different stages of the estrous cycle. $\mathrm{A}$ pH-sensitive fluorescent dye 5 - $\mathrm{N}$-hexadecanoyl-aminofluorescein (HAF), which attaches to the luminal surface of the endometrium due to its lipophilic characteristic, was used for the measurement of the epithelial surface $\mathrm{pH}$ at estrus and diestrus. As shown in Fig. 2A, the fluorescence ratio measured from the uteri of estrus was significantly higher than that of diestrus $(P<0.01)$, indicating that the basal uterine luminal $\mathrm{pH}$ at estrus was more alkaline than that at diestrus. The uterine luminal surface fluorescence intensity ratio at estrus could be reduced by the inhibitors of CFTR, SLC26A6 and CA, 

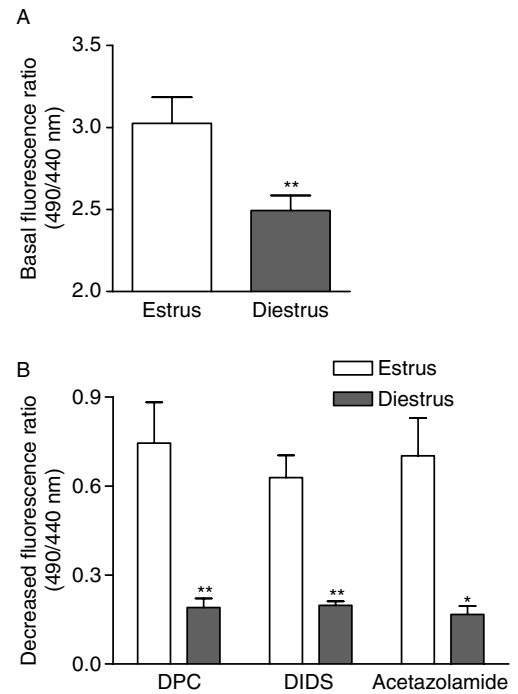

Figure 2 Comparison of resting uterine luminal surface $\mathrm{pH}$ (fluorescence ratio) and the effect of bicarbonate transport proteins at estrus and diestrus. Each data point was obtained from at least four individual mice. Uterine tissues collected at estrus and diestrus were labeled with HAF and were superfused with normal K-H solution. A significantly higher uterine luminal surface $\mathrm{pH}$, indicated by larger fluorescence ratio, at estrus as compared with that at diestrus was observed $\left({ }^{* *} P<0.01, n=4\right)(\mathrm{A})$. Decrease in luminal surface $\mathrm{pH}$ (fluorescence ratio) could be induced by CFTR blocker, DPC $\left(1 \mathrm{mM}\right.$; $\left.{ }^{* *} P<0.01, n=4\right)$, SLC26A6 inhibitor, DIDS $(100 \mu \mathrm{M}$; $\left.{ }^{* *} P<0.01, n=4\right)$, and CA inhibitor, acetazolamide $(100 \mu \mathrm{M}$; $\left.{ }^{*} P<0.05, n=4\right)$, to a significantly larger extent at estrus compared with that at the diestrus (B).

diphenylamine-2,2'-dicarboxylic acid (DPC; $P<0.01$ ), $4^{\prime}, 4^{\prime}$-diisothiocyanostilbene-2' $2^{\prime} 2^{\prime}$-disulfonic acid (DIDS; $P<0.01)$, and acetazolamide $(P<0.05$; Fig. $2 \mathrm{~B})$ respectively to a significant larger extent as compared with that observed at diestrus, indicating more active bicarbonate secretion at estrus.

\section{Effect of exogenously administered estrogen on uterine bicarbonate-dependent current in OVX mice}

The serum level of the mouse ovarian hormone, estrogen, fluctuates during the estrous cycle, with a $40 \%$ increase from proestrus to estrus and a decline after ovulation at metestrus and diestrus (Fata et al. 2001). Since a high level of estrogen at estrus had been demonstrated to be responsible for the maximal expression level of CFTR observed at estrus (Rochwerger \& Buchwald 1993, Rochwerger et al. 1994, Chan et al. 2002), we hypothesized that other bicarbonate transport/ production proteins may also be upregulated by the high level of estrogen at estrus. As shown in Fig. 3, the magnitude of the forskolin $\left(10^{-6} \mathrm{M}\right)$-induced bicarbonate-dependent $I_{\mathrm{sc}}$, which was measured in $\mathrm{Cl}^{-}$-free bathing solution, increased as the dose of the administered estrogen was increased.

\section{Effect of estrogen on surface $\mathrm{pH}$ of primary culture of mouse endometrial epithelial cells}

An in vitro model of endometrial epithelial cells was established for surface $\mathrm{pH}$ measurement to further illustrate the effect of estrogen on the endometrial bicarbonate secretion. Mouse endometrial epithelial cells were seeded onto Transwell filters and cultured for 3 days to confluence with $17 \beta$-estradiol $\left(E_{2} ; 100 \mathrm{nM}\right)$ in the culture medium for $24 \mathrm{~h}$ prior to the experiment. The surface $\mathrm{pH}$ was detected continuously by fluorescent dye HAF. Statistic analysis (Fig. 4) showed that the basal $\mathrm{pH}$ of the estrogen-treated endometrial epithelial cells was significantly higher than that of nontreated ones $(P<0.01)$, indicating enhanced bicarbonate transport upon estrogen treatment.

\section{Effect of estrogen receptor antagonist}

Major biological effects of estrogen in the uterus are thought to be primarily mediated by nuclear estrogen receptors, ESR1 (ER $\alpha)$ and ESR2 $(E R \beta)$. To examine whether

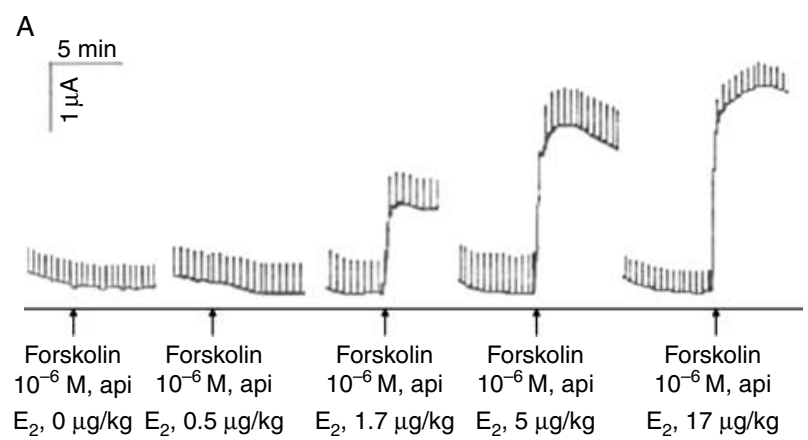

B

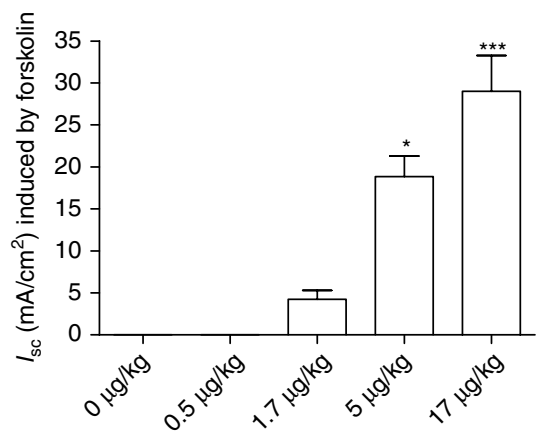

Figure 3 Effect of exogenously administered estrogen on the forskolin $\left(10^{-6} \mathrm{M}\right)$-induced bicarbonate-dependent $I_{\mathrm{sc}}$ in OVX mice. OVX mice were divided into five groups, each received daily i.p. injection of $17 \beta$-estradiol of different dosages, $0.5,1.7,5$, and $17 \mu \mathrm{g} / \mathrm{kg}$, with the control group receiving vehicle ( $1 \%$ alcohol in saline) for 2 days. Uterine tissues were collected $24 \mathrm{~h}$ after the last treatment for $I_{\mathrm{sc}}$ measurement. (A) Representative recordings of $I_{\mathrm{sc}}$ responses to forskolin added to the apical side of the endometria from mice treated with different doses of estrogen. Arrowheads indicate the time of forskolin addition.

(B) Statistical analysis of forskolin-elicited $I_{\mathrm{sc}}\left(\mu \mathrm{A} / \mathrm{cm}^{2}\right)$ mainly mediated by bicarbonate ion response to different dose of estrogen in $\mathrm{Cl}^{-}$-free solution. Each point was obtained from at least four individual experiments. Values are means \pm s.E.M. of maximal increase in $I_{\text {sc }}{ }^{*} P<0.05,{ }^{* * *} P<0.001$. 


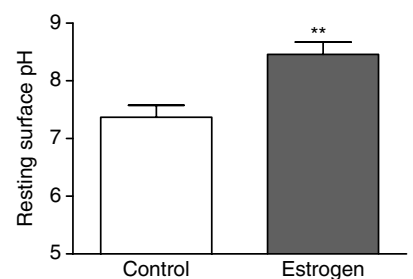

Figure 4 Effect of estrogen on the resting surface $\mathrm{pH}$ of cultured mouse endometrial epithelial cells. The primary culture of the endometrium from immature ICR female mice seeded to Transwell filter was cultured for 3-4 days to confluent, then treated with $E_{2}(100 \mathrm{nM})$ and vehicle as control in the culture medium for $24 \mathrm{~h}$. With HAF loaded at the luminal surface, the resting surface $\mathrm{pH}$ of the endometrium was detected in normal K-HS superfusion. Statistic analysis showed that the basal $\mathrm{pH}$ of the endometrium is significantly higher $\left({ }^{* *} P<0.01, n=6\right)$ in $\mathrm{E}_{2}$-treated group compared with control.

the estrogen-induced responses observed above were through its receptor-mediated action, OVX mice were given a daily injection of $E_{2}$ with or without ICI 182780 (a potent antiestrogen for both ESR1 and ESR2) with the control injected with solvent vehicle for 2 days, and the uterine tissues were collected at $2400 \mathrm{~h}$ after the last injection. Uterine expression of CFTR, SLC26A6, CAR2, and CAR12 in OVX mice treated with vehicle, $E_{2}$, or $E_{2}$ plus ICI 182780 was analyzed by western blot. As shown in Fig. 5A and $\mathrm{B}$, the uterine expression levels of the bicarbonate transport/production-related proteins were higher in $E_{2}$-treated OVX mice compared with the controls, which could be suppressed by the treatment with ICI 182780 , confirming a receptor-mediated upregulating effect of $E_{2}$ on the bicarbonate-related proteins in the endometrium. The $I_{\mathrm{sc}}$ measurement showed that the forskolin $\left(10^{-6} \mathrm{M}\right)$-induced bicarbonate section was only detected in OVX mice uterus treated with $\mathrm{E}_{2}$, but not in those treated with vehicle or $\mathrm{E}_{2}$ plus ICI 182780 (Fig. 5C).

\section{Discussion}

Estrogen is produced cyclically by the ovaries and plays a crucial role in maintaining and regulating the functions of the female reproductive system. The complex events during the estrous cycle under the influence of estrogen have been a focus of attention; however, how estrogen regulates the uterine fluid environment, especially its composition, remains largely unknown. This study is the first to show that estrogen, in an estrogen receptordependent manner, upregulates bicarbonate transport/ production proteins in mouse endometrium, providing new insights into our current understanding of the role of estrogen in regulating uterine bicarbonate transport.

Bicarbonate plays a surprisingly important role in a number of reproductive events, including sperm capacitation and embryo development (Lee \& Storey 1986, Tajima et al. 1987, Visconti et al. 1995). It was reported half a century ago that the bicarbonate concentration in the female reproductive tract varies and closely depends on reproductive events, i.e. increased bicarbonate during fertilization (Blandau et al. 1958); however, the molecular mechanism underlying the formation of bicarbonate-rich uterine fluid and its regulation remains largely unknown. Previously, we have established a primary culture of mouse endometrial epithelial cells (Chan et al. 1997) and used it to study possible transporters involved in uterine bicarbonate secretion (Wang et al. 2002) and its significance in determining the fertilizing capacity of sperm (Wang et al. 2003). However, the primary culture has its limitations. First, the epithelial cells have to be isolated from sexually immature mouse uteri in order to enable proliferation in culture, which may not have the same gene expression profile as in mature mice. Secondly, some protein expression or function may be lost during the culture as observed in many cell cultures including human fallopian tubule cells (Downing et al. 1997). Most importantly, the culture condition cannot reproduce the cyclic characteristics normally observed in vivo, considering the fluctuating levels of ovarian hormones. Therefore, the need to study bicarbonate transport mechanisms in vivo is evident.

In this study under physiological conditions, we have found that uterine bicarbonate secretion and the expression of the bicarbonate transport/production proteins exhibit cyclic variations throughout the estrous cycle in mice. We note that the maximal protein expression levels are observed at estrus, which is consistent with the rise of estrogen level at estrus. The expression profile of the bicarbonate transport/production-related proteins agrees well with the results obtained by the $I_{\mathrm{sc}}$ and luminal surface $\mathrm{pH}$ measurement, showing alkaline $\mathrm{pH}$ at the luminal surface at estrus while minimal $\mathrm{pH}$ value observed at diestrus. The sensitivity of the alkaline $\mathrm{pH}$ to the inhibitors of CFTR, SLC26A6, and CA suggests that these proteins are functional and involved in bicarbonate transport/ production in the endometrial epithelium. Taken together, these results indicate more active bicarbonate secretion at estrus and suggest the possible involvement of estrogen in regulating the expression of the bicarbonate transport/production-related proteins and thus the formation of a bicarbonate-rich fluid environment.

This study has further established a positive link between the circulating serum estrogen levels and uterine bicarbonate secretion as demonstrated by a dose dependency of the uterine forskolin-activated bicarbonate-dependent $I_{\mathrm{sc}}$ on exogenously administered estrogen to the OVX mouse. This effect of estrogen on uterine bicarbonate secretion appears to be mediated by upregulation of bicarbonate transport/production proteins as demonstrated by the observation that the primary culture of endometrium epithelial cells treated with estrogen exhibits higher luminal surface $\mathrm{pH}$ than the control, with upregulated bicarbonate 
A

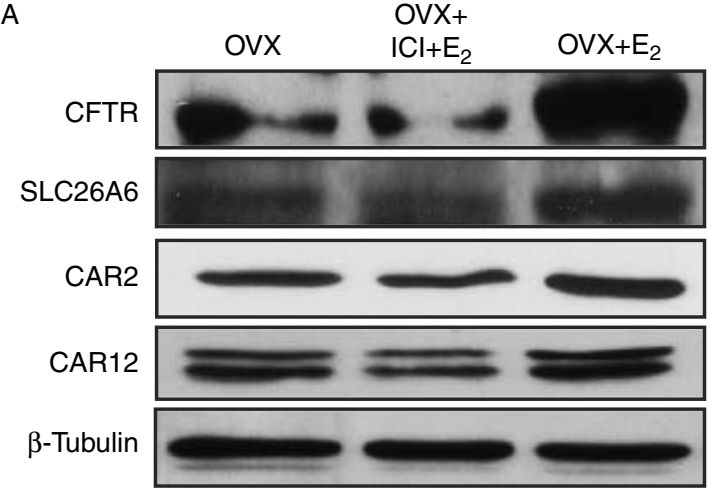

B

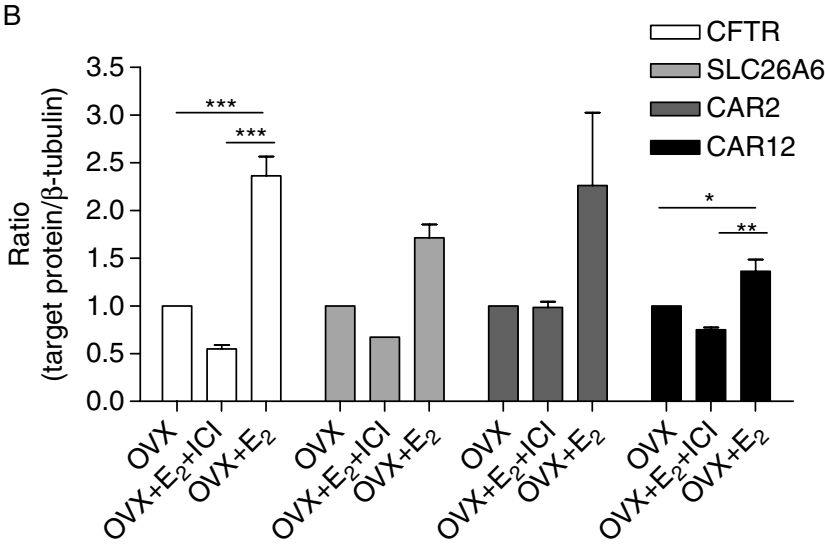

C

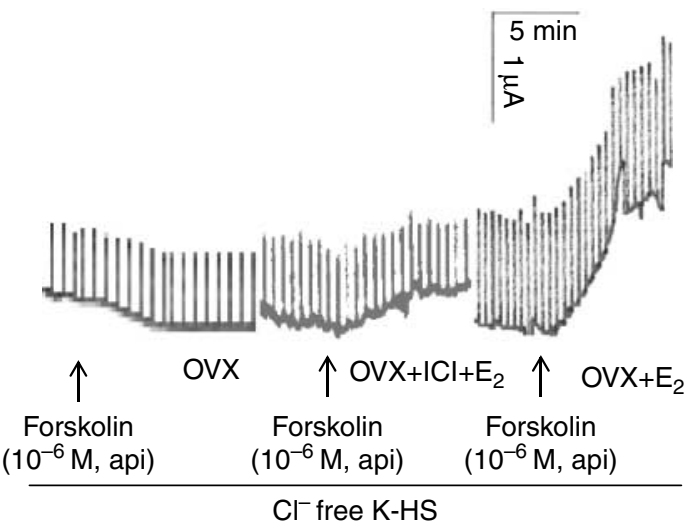

Figure 5 Effect of estrogen and estrogen receptor antagonist on uterine bicarbonate transport and related proteins' expression in OVX mice uteri. (A) Representative photo of western blot analysis on CFTR, SLC26A6, CAR2, and CAR12 expression in the uteri from OVX mice treated with vehicle, $E_{2}$, or $\mathrm{E}_{2}$ plus $\mathrm{ICI} 182780(\mathrm{ICl}) . \beta$-Tubulin was used as loading control. Lane 1: OVX mice treated with vehicle. Lane 2: $E_{2}$ plus ICl. Lane 3: $E_{2}$. Treatment of OVX mice with $\mathrm{E}_{2}$ alone produced an obvious increase in CFTR, SLC26A6, CAR2, and CAR12 protein level as compared with the OVX mice treated with vehicle or $\mathrm{E}_{2}$ plus $\mathrm{ICl}$ respectively ( $n=4$ for each group). (B) Quantitation of western blot analysis of estrogen effect on CFTR, SLC26A6, CAR2, and CAR12 expression. ${ }^{*} P<0.05,{ }^{* *} P<0.01,{ }^{* * *} P<0.001$. (C) Representative traces of $I_{\mathrm{sc}}$ response to forskolin $\left(10^{-6} \mathrm{M}\right)$ in chloride-free solution. The OVX mice were given daily injection of $\mathrm{E}_{2}$ with or without $\mathrm{ICl}$ with the control injected with vehicle for 2 days, and uterine tissues were collected at $24 \mathrm{~h}$ after the last injection and subjected to $I_{\mathrm{sc}}$ measurement. The forskolininduced bicarbonate secretion was only detected in OVX mice uterus treated with $\mathrm{E}_{2}$ (middle trace), but not in those treated with vehicle (left trace) or $\mathrm{E}_{2}$ plus $\mathrm{ICI}$ (right trace). Arrowheads indicate the time of forskolin addition. transport/production proteins' expression. These findings are consistent with the previous finding that administration of estrogen to immature and OVX mature female rats leads to the induction of CFTR expression (Rochwerger et al. 1994). As CFTR has been shown to conduct bicarbonate (Poulsen et al. 1994, Hug et al. 2003) and demonstrated to be involved in uterine bicarbonate secretion (Wang et al. 2003), the presently observed co-expression of CFTR with other bicarbonate transport/production genes in response to estrogen stimulation further supports the important role of CFTR in bicarbonate secretion and its regulation by estrogen. It should be noted that major biological effects of estrogen in the uterus are thought to be primarily mediated via a process that involves estrogen binding to nuclear estrogen receptors, ESR1 or ESR2 in target cells, which leads to gene transcription and, subsequently, to a modification of cellular responses. Using the OVX mouse model administered with both $\mathrm{E}_{2}$ and estrogen receptor antagonist $\mathrm{ICl} 182780$, we show in this study that the upregulated bicarbonate secretion and related proteins expression are indeed stimulated by estrogen and mediated by estrogen receptor, although the specific receptor subtype involved remains to be elucidated.

It should be noted that there are at least two ways for bicarbonate to accumulate in the endometrial epithelial cells. Previous studies on the primary culture of mouse endometrial epithelial cells have demonstrated that bicarbonate can be taken into the cells via $\mathrm{Na}^{+}-\mathrm{HCO}_{3}^{-}$ co-transporter (Wang et al. 2002). This study suggests that bicarbonate production through $\mathrm{CO}_{2}$ hydration is also important because two isoforms of CAs expressed in the endometrial epithelial cells are upregulated at estrus and by estrogen. Although a $\mathrm{Cl}^{-} / \mathrm{HCO}_{3}^{-}$exchanger has been implicated in uterine bicarbonate secretion previously (Wang et al. 2003), its molecular identity has not been demonstrated. This study is the first to examine the expression of a potential candidate, SLC26A6, in the endometrial epithelial cells and the co-expression of SLC26A6 with CFTR and CAs in response to estrogen supports its involvement in uterine bicarbonate secretion. In addition to a direct role of CFTR in mediating bicarbonate exit of the cells, it may also work with SLC26A6 as a $\mathrm{Cl}^{-}$channel, providing a $\mathrm{Cl}^{-}$ recycling pathway in order to sustain the operation of the $\mathrm{Cl}^{-} / \mathrm{HCO}_{3}^{-}$exchanger, as established in pancreatic bicarbonate secretion (Hug et al. 2003). The enhanced production of bicarbonate, as indicated by upregulated CAs expression, and increased bicarbonate transport, as indicated by the upregulation of the transporter proteins and results of the $I_{\mathrm{sc}}$ and $\mathrm{pH}$ measurement, either at estrous or in response to estrogen stimulation, suggest an important role of estrogen in stimulating uterine bicarbonate secretion at estrus, a time immediately prior to ovulation. As bicarbonate is known to promote sperm motility and capacitation, a process by which sperm acquire their ability to fertilize the egg, the 
enhanced uterine bicarbonate secretion at estrus is a necessary process to enable sperm to acquire their fertilizing capacity and thus important for fertility. Therefore, in addition to its well-known effect on proliferation of the endometrium, estrogen may also play an important role in regulating uterine fluid environment, both in volume as suggested previously (Chan et al. 2002) and bicarbonate content as demonstrated by the results of this study. The upregulated CFTR at estrus appears to play a dual role. On the one hand, as a $\mathrm{Cl}^{-}$channel it promotes $\mathrm{Cl}^{-}$secretion and thus providing the driving force for fluid secretion, leading to a large fluid volume increase normally observed around estrus, which may facilitate sperm transport. On the other hand, being involved in bicarbonate transport, either directly as demonstrated previously (Wang et al. 2003) or indirectly working in parallel with the $\mathrm{Cl}^{-} / \mathrm{HCO}_{3}^{-}$exchanger, possibly SLC26A6, as in the pancreas (Hug et al. 2003), CFTR plays an indispensable role in uterine bicarbonate secretion on which sperm function and reproduction depend. It should be noted that while sperm capacitation is traditionally considered to take place in the oviduct, the present finding, as well as the demonstration reported previously (Wang et al. 2003), suggests that the process may also begin in the uterus to prepare sperm for their travel through the oviduct, as hyperactivation is one of the consequences of capacitation.

In summary, this study has demonstrated for the first time the differential expression of CFTR, SLC26A6, CAR2, and CAR12, and their involvement in $\mathrm{HCO}_{3}^{-}$ secretion in the murine uterus during the estrous cycle, with demonstrated effect of estrogen on upregulation of their expression and $\mathrm{HCO}_{3}^{-}$secretion. Together, with its well-known action on proliferation of the endometrial lining and follicle development, estrogen also appears to exert its influence on sperm through uterine bicarbonate secretion necessary for sperm motility and capacitation. Therefore, the present findings suggest that the precise and coordinated control of estrogenregulated $\mathrm{HCO}_{3}^{-}$secretion is essential to the success of reproduction.

\section{Materials and Methods}

\section{Chemicals}

DPC was obtained from Riedel de Haen Chemicals (Hannover, Germany). Forskolin, DIDS, and acetazolamide were purchased from Sigma-Aldrich Co. Stock solutions of all the chemicals were dissolved in DMSO. Final DMSO concentrations never exceeded $1 \%(\mathrm{v} / \mathrm{v})$. Preliminary experiments indicated that the vehicle did not alter any baseline electrophysiological or fluorescence parameters (data not shown).

\section{Animals}

Female imprinting control region (ICR) mice were provided by the Laboratory Animal Service Center of the Chinese University of Hong Kong. They were maintained in an air-conditioned room with controlled temperature of $24 \pm 2{ }^{\circ} \mathrm{C}$ and humidity of $55 \pm 15 \%$, in a $1200 \mathrm{~h}$ light/darkness cycle regulation and were fed laboratory chow and water ad libitum. Ethics committee approval was obtained before this study, and all animal experiments were conducted in accordance with the University Laboratory Animals Service Center's guidelines on animal experimentation with approval from the Animal Ethnics Committee of the University. Three- to four-weeks-old immature female mice were used for endometrial epithelial cell culture. Eight- to ten-weeks-old sexually mature female mice were used for protein and functional study.

\section{Determination of the estrous cycle}

Stages of the estrous cycle encompassing proestrus, estrus, metestrus, and diestrus were determined by cytological evaluation of vaginal smears on 8-10-weeks-old sexually mature ICR mice as described previously (Rugh 1980). Mice undergoing normal estrous cycle changes over at least two cycles were included in further studies. Vaginal smears were observed twice daily at 0900 and $1200 \mathrm{~h}$, and those exhibiting a stage change at noon were divided into diestrus, proestrus, or metestrus groups and were killed immediately. Thus, all samples collected are representative of the initial onset of each stage, and this regimen minimized the expected intrastage variation. As mice enter estrus in the early hours of the night, vaginal smears were obtained at 2100 and $0900 \mathrm{~h}$, and those mice that entered estrus from proestrus overnight were euthanized immediately.

\section{Ovariectomy and estrogen treatment}

Eight- to ten-weeks-old sexually mature mice were bilaterally OVX under ketamine $(75 \mathrm{mg} / \mathrm{kg}$ i.p.) and xylasine $(10 \mathrm{mg} / \mathrm{kg}$ i.p.) anesthesia and left to recover for 3 weeks. Mice were then divided into six groups; each received daily i.p. injection of $E_{2}$ (100 $\mu \mathrm{l}$, Sigma-Aldrich) of different dosages, $0.5,1.7,5$, and $17 \mu \mathrm{g} / \mathrm{kg}$ with the control group receiving vehicle (1\%o alcohol in saline) for 2 days. When mice were treated with $E_{2}$ plus $\mathrm{ICI}$ 182780 (Sigma-Aldrich), a potent antiestrogen for both ESR1 and ESR2, $17 \mathrm{mg} / \mathrm{kg}$ of ICI 182780 was injected 30 min before $\mathrm{E}_{2}(1.7 \mu \mathrm{g} / \mathrm{kg})$ injection. Animals were killed $24 \mathrm{~h}$ after the treatment and their uteri were removed for $I_{\mathrm{sc}}$ or frozen in liquid nitrogen and stored at $-70{ }^{\circ} \mathrm{C}$ for western blot analysis.

\section{Endometrial epithelia cell culture}

Endometrial epithelial cells were enzymatically isolated from the mouse uterus according to the method described by McCormack \& Glasser (1980) with slight modifications, which produced pure epithelia identified by epithelial cell markers (Chan et al. 1997). Samples of uteri were obtained from 3.5- to 4-week-old immature ICR mice to avoid the complication of the endometrial cycle. Animals were killed by placing them in 
a $\mathrm{CO}_{2}$-gassed chamber for $3 \mathrm{~min}$. Uteri were removed and placed into a Petri dish containing sterile PBS (without $\mathrm{Ca}^{2+}$ and $\mathrm{Mg}^{2+}$ ). After washing with PBS and trimming off the remaining fatty and connective tissues, the uteri were sliced longitudinally. The sliced uteri were incubated in PBS supplemented with $7.5 \mathrm{mg} / \mathrm{ml}$ trypsin (Gibco Laboratory), $25 \mathrm{mg} / \mathrm{ml}$ pancreatin (Gibco Laboratory), $100 \mathrm{U} / \mathrm{ml}$ penicillin, and $100 \mu \mathrm{g} / \mathrm{ml}$ streptomycin (Gibco Laboratory) at $0{ }^{\circ} \mathrm{C}$ for $60 \mathrm{~min}$ and then at room temperature for another $60 \mathrm{~min}$. After the enzyme digestion, the test tube containing PBS and the tissues was shaken gently for $30 \mathrm{~s}$. Uterine tissue was carefully removed and the crude cell solution was passed through a $70 \mathrm{~mm}$ fluorocarbon mesh filter (Spectra Mesh; Spectrum, Houston, TX, USA). The filtrate was centrifuged at $1000 \mathrm{~g}$ for $5 \mathrm{~min}$. The supernatant was discarded and the cell pellet was re-suspended in $12 \mathrm{ml}$ PBS. The cells were allowed to settle for $5 \mathrm{~min}$, and then the top portion (about $2 \mathrm{ml}$ ) of the cell suspension was discarded. The cell suspension was centrifuged again at $1000 \mathrm{~g}$ for $5 \mathrm{~min}$. The washing procedures were then repeated once more. After centrifugation, the cell pellet was re-suspended in phenol-red-free Ham's F12-DMEM culture medium (Gibco Laboratory) containing 10\% (v/v) charcoal/ dextran-treated fetal bovine serum (Hyclone, Logan, UT, USA), $1 \%(\mathrm{v} / \mathrm{v})$ nonessential amino acids, $100 \mathrm{U} / \mathrm{ml}$ penicillin, and $100 \mathrm{mg} / \mathrm{ml}$ streptomycin. The isolated endometrial cells were plated at $1.5 \times 10^{6}$ cells $/ \mathrm{ml}$ on Transwell-Col membranes with pores of $0.45 \mathrm{~mm}$ (Corning Incorporated, Corning, NY, USA). Cultures were incubated at $37{ }^{\circ} \mathrm{C}$ in $95 \% \mathrm{O}_{2} / 5 \% \quad \mathrm{CO}_{2}$ and reached confluence in 3 days. Epithelial luminal surface $\mathrm{pH}$ was measured on the third day of culture and $E_{2}$ was added to some wells $24 \mathrm{~h}$ prior to apical $\mathrm{pH}$ measurement.

\section{Western blot analysis}

Snap-frozen uterine tissues were ground thoroughly with a pestle in liquid nitrogen cooled condition. Uteri from six sexually mature mice at the same estrous cycle were mixed together. RIPA lysis buffer and protease inhibitors were added then. The whole cell lysates were obtained by centrifugation at $13000 \mathrm{~g}$ for $30 \mathrm{~min}$ at $4{ }^{\circ} \mathrm{C}$. After the protein concentration was determined, the cell lysates containing equal amounts of protein were loaded onto $8-12 \%$ SDS-PAGE. Blots were incubated with monoclonal mouse anti-mouse CFTR antibody by 1:500 dilution (Alexis Biochemicals Corporation, San Diego, CA, USA) and rabbit anti-mouse $\beta$-tubulin by 1:2000 dilution (Santa Cruz Biotechnology, Santa Cruz, CA, USA). Polyclonal rabbit anti-mouse CAR2 (1:200 dilution) and CAR12 (1:200 dilution) antibodies were kindly supplied by Prof. W S Sly and J Grubb from St Louis University, USA. Monoclonal rabbit antimouse SLC26A6 (1:200 dilution) antibody was kindly supplied by Prof. Z H Wang from the University of California, USA. ECL was visualized by film development.

\section{Short-circuit current measurement}

$I_{\mathrm{sc}}$ measurement has previously been described (Ussing \& Zerahn 1951). In brief, freshly removed endometrial epithelia from which the serosa and muscular layers had been removed were clamped vertically between two halves of the Ussing chamber. The epithelia were bathed on both sides with Krebs-Henseleit solution (K-HS) that was maintained at $37^{\circ} \mathrm{C}$. The K-HS had the following composition: $117 \mathrm{mM} \mathrm{NaCl}$, $4.7 \mathrm{mM} \mathrm{KCl}, 2.5 \mathrm{mM} \mathrm{CaCl}_{2}, 1.2 \mathrm{mM} \mathrm{MgCl}_{2}, 24.8 \mathrm{mM}$ $\mathrm{NaHCO}_{3}, 1.2 \mathrm{mM} \mathrm{KH}_{2} \mathrm{PO}_{4}$, and $11.1 \mathrm{mM}$ glucose. $\mathrm{Cl}^{-}$in $\mathrm{Cl}^{-}$-free $\mathrm{K}-\mathrm{H}$ solution was substituted with gluconate salts, which had the following compositions (mM): Na-gluconate, 117; K-gluconate, 4.7; $\mathrm{MgSO}_{4}, 1.2 ; \mathrm{KH}_{2} \mathrm{PO}_{4}, 1.2 ; \mathrm{NaHCO}_{3}, 24.8$; Ca-gluconate, 2.56; glucose, 11.1. The $\mathrm{pH}$ value of normal $\mathrm{K}-\mathrm{HS}$ and $\mathrm{Cl}^{-}$-free $\mathrm{K}-\mathrm{HS}$ was maintained at 7.4 when gassed with $95 \% \mathrm{O}_{2} / 5 \% \mathrm{CO}_{2}$. Drugs were added directly to the apical side of the epithelium. The transepithelial potential differences exhibited by the epithelia were measured by the $\mathrm{Ag} / \mathrm{AgCl}$ electrodes (World Precision Instruments, Sarasota, FL, USA) connected to a preamplifier, which was connected to a voltage clamp amplifier (DVC 1000, World Precision Instruments). The change in $I_{\mathrm{sc}}$ was defined as the maximal rise in $I_{\mathrm{sc}}$ after agonist stimulation and was normalized as current change per unit area of the uterine epithelium $\left(\mu \mathrm{A} / \mathrm{cm}^{2}\right)$.

\section{Luminal surface $p H$ measurement}

The $\mathrm{pH}$-sensitive fluorescent dye HAF (Invitrogen) molecule consists of two domains, the fluorescein molecule and a palmitoyl chain connected to this fluorescing moiety. Dragsten et al. (1981) have shown that this palmitoyl chain inserts into the apical membrane of cells due to its lipophilic character. The sensitivity of HAF to $\mathrm{pH}$ changes relies on the presence of dissociable groups in the fluorescing moiety. A section of the uterus was cut open longitudinally. The mucosa was stripped off the serosa and muscular layers with fine forceps, and then the stripped epithelium fixed to the supporting ring was placed in a specially designed microperfusion chamber with the lumen side uppermost. Primary cultures of the endometrial epithelial cells were grown for 4 days on clear Transwell-Col membranes (Corning Incorporated) with pores of $0.45 \mu \mathrm{m}$. A final HAF concentration of $15 \mu \mathrm{mol} / \mathrm{I}$ was used to incubate the mucosal side of the endometrial tissue or cultured cells in the dark for $5 \mathrm{~min}$ at $37^{\circ} \mathrm{C}$, and then the endometrial epithelial cells were washed thoroughly and perfused with normal K-HS (carbogen gassed, $37^{\circ} \mathrm{C}$ ) to rinse away unbound dye. The measurement of luminal surface $\mathrm{pH}$ was recorded in an inverted Olympus IX70 microscope equipped with a CCD camera. Fluorescence was recorded in the images of the HAF signals that were obtained by excitation wavelength at 440 and $490 \mathrm{~nm}$. The ratio of these two signals was directly proportional to the $\mathrm{pH}$ and the images were captured by using MetaFluro from Universal Imaging Corp. (Washington, DC, USA). For calibrations, nigericin $(10 \mu \mathrm{g} / \mathrm{l})$ was added to the calibration buffers containing (in mmol/l) 152 $\mathrm{Cl}^{-}, 133.4 \mathrm{~K}^{+}, 25 \mathrm{HEPES}, 15 \mathrm{Na}^{+}, 1.8 \mathrm{Ca}^{2+}, 0.8 \mathrm{Mg}^{2+}$, and $0.8 \mathrm{SO}_{4}^{2-}$. The $\mathrm{pH}$ of these solutions was adjusted to a defined $\mathrm{pH}$ in the range $6.0-8.0$ by different amounts of $1 \mathrm{M} \mathrm{KOH}$. The osmolarity of the buffers was $300 \mathrm{mosmol} / \mathrm{l}$.

\section{Statistical analysis}

Results are expressed as means \pm S.E.M., and $n$ indicates the number of experiments. Statistical analysis was carried out by Prism (GraphPad, Inc., San Diego, CA, USA). Comparisons 
between two groups of data were carried out using Student's $t$-test. Comparisons among three or more groups of the data were carried out using one-way ANOVA, followed by Newman-Keul's multiple range test. A $P$ value $<0.05$ was considered statistically significant.

\section{Declaration of interest}

The authors declare that there is no conflict of interest that could be perceived as prejudicing the impartiality of the research reported.

\section{Funding}

This work was supported by the National 973 project (No. 2006CB504002), the National Science Foundation of China (No. 30900511), the Focused Investment Scheme, and the Li Ka Shing Institute of Health Sciences of The Chinese University of Hong Kong.

\section{References}

Aitken RJ 1979 Tubal and uterine secretion: the possibilities for contraceptive attack. Journal of Reproduction and Fertility 55 247-254. (doi:10. 1530/jr.0.0550247)

Blandau R, Jensen L \& Rumery R 1958 Determination of the $\mathrm{pH}$ values of the reproductive-tract fluids of the rat during heat. Fertility and Sterility $\mathbf{9}$ 207-214.

Chan HC, Liu CQ, Fong SK, Law SH, Leung PS, Leung PY, Fu WO, Cheng Chew SB \& Wong PY 1997 Electrogenic ion transport in the mouse endometrium: functional aspects of the cultured epithelium. Biochimica et Biophysica Acta 1356 140-148. (doi:10.1016/S0167-4889(96)00171-1)

Chan LN, Tsang LL, Rowlands DK, Rochelle LG, Boucher RC, Liu CQ \& Chan HC 2002 Distribution and regulation of ENaC subunit and CFTR mRNA expression in murine female reproductive tract. Journal of Membrane Biology 185 165-176. (doi:10.1007/s00232-001-0117-y)

Downing SJ, Maguiness SD, Watson A \& Leese HJ 1997 Electrophysiological basis of human fallopian tubal fluid formation. Journal of Reproduction and Fertility 111 29-34. (doi:10.1530/jrf.0.1110029)

Dragsten PR, Blumenthal R \& Handler JS 1981 Membrane asymmetry in epithelia: is the tight junction a barrier to diffusion in the plasma membrane? Nature 294 718-722. (doi:10.1038/294718a0)

Evans HM \& Long JA 1922 Characteristic effects upon growth, oestrus and ovulation induced by the intraperitoneal administration of fresh anterior hypophyseal substance. PNAS 8 38-39. (doi:10.1073/pnas.8.3.38)

Fata JE, Chaudhary V \& Khokha R 2001 Cellular turnover in the mammary gland is correlated with systemic levels of progesterone and not $17 \beta$ estradiol during the estrous cycle. Biology of Reproduction 65 680-688. (doi:10.1095/biolreprod65.3.680)

Hug MJ, Tamada T \& Bridges RJ 2003 CFTR and bicarbonate secretion to epithelial cells. News in Physiological Sciences 18 38-42. (doi:10.1152/ nips.01412.2002)

Kane MT 1975 Bicarbonate requirements for culture of one-cell rabbit ova to blastocysts. Biology of Reproduction 12 552-555. (doi:10.1095/ biolreprod12.5.552)

Kopito LE, Kosasky HJ \& Shwachman H 1973 Water and electrolytes in cervical mucus from patients with cystic fibrosis. Fertility and Sterility $\mathbf{2 4}$ $512-516$.

Lee MA \& Storey BT 1986 Bicarbonate is essential for fertilization of mouse eggs: mouse sperm require it to undergo the acrosome reaction. Biology of Reproduction 34 349-356. (doi:10.1095/biolreprod34.2.349)

Markovich D 2001 Physiological roles and regulation of mammalian sulfate transporters. Physiological Reviews 81 1499-1533.
McCormack SA \& Glasser SR 1980 Differential response of individual uterine cell types from immature rats treated with estradiol. Endocrinology 106 1634-1649. (doi:10.1210/endo-106-5-1634)

Mukherjee T, Copperman AB, McCaffrey C, Cook CA, Bustillo M \& Obasaju MF 1996 Hydrosalpinx fluid has embryotoxic effects on murine embryogenesis: a case for prophylactic salpingectomy. Fertility and Sterility 66 851-853.

Mularoni A, Beck L, Sadir R, Adessi GL \& Nicollier M 1995 Downregulation by progesterone of CFTR expression in endometrial epithelial cells: a study by competitive RT-PCR. Biochemical and Biophysical Research Communications 217 1105-1111. (doi:10.1006/bbrc.1995. 2883)

Murdoch RN \& White IG 1968 The influence of the female genital tract on the metabolism of rabbit spermatozoa. I. Direct effect of tubal and uterine fluids, bicarbonate, and other factors. Australian Journal of Biological Sciences 21 961-972.

Poulsen JH, Fischer H, Illek B \& Machen TE 1994 Bicarbonate conductance and $\mathrm{pH}$ regulatory capability of cystic fibrosis transmembrane conductance regulator. PNAS 91 5340-5344. (doi:10.1073/pnas.91.12. 5340)

Rochwerger L \& Buchwald M 1993 Stimulation of the cystic fibrosis transmembrane regulator expression by estrogen in vivo. Endocrinology 133 921-930. (doi:10.1210/en.133.2.921)

Rochwerger L, Dho S, Parker L, Foskett JK \& Buchwald M 1994 Estrogendependent expression of the cystic fibrosis transmembrane regulator gene in a novel uterine epithelial cell line. Journal of Cell Science $\mathbf{1 0 7}$ 2439-2448.

Rugh R 1980 Reproductive systems of adult mice. In The Mouse: Its Reproduction and Development, ch 2, pp 7-43. Ed. R Rugh. New York: Oxford University Press.

Sterling D \& Casey JR 2002 Bicarbonate transport proteins. Biochemistry and Cell Biology 80 483-497. (doi:10.1139/o02-152)

Suarez SS \& Ho HC 2003 Hyperactivated motility in sperm. Reproduction in Domestic Animals 38 119-124. (doi:10.1046/j.1439-0531.2003. 00397.X)

Tajima Y, Okamura N \& Sugita Y 1987 The activating effects of bicarbonate on sperm motility and respiration at ejaculation. Biochimica et Biophysica Acta 924 519-529. (doi:10.1016/0304-4165(87)90168-1)

Ussing HH \& Zerahn K 1951 Active transport of sodium as the source of electric current in the short-circuited isolated frog skin. Acta Physiologica Scandinavica 23 110-127. (doi:10.1111/j.1748-1716.1951.tb00800.x)

Visconti PE, Bailey JL, Moore GD, Pan D, Olds-Clarke P \& Kopf GS 1995 Capacitation of mouse spermatozoa. I. Correlation between the capacitation state and protein tyrosine phosphorylation. Development 121 1129-1137.

Visconti PE, Stewart-Savage J, Blasco A, Battaglia L, Miranda P, Kopf GS \& Tezón JG 1999 Roles of bicarbonate, cAMP, and protein tyrosine phosphorylation on capacitation and the spontaneous acrosome reaction of hamster sperm. Biology of Reproduction 61 76-84. (doi:10.1095/ biolreprod61.1.76)

Vishwakarma P 1962 The $\mathrm{pH}$ and bicarbonate-ion content of the oviduct and uterine fluids. Fertility and Sterility 13 481-485.

Wang XF, Yu MK, Leung KM, Yip CY, Ko WH, Liu CQ \& Chan HC 2002 Involvement of $\mathrm{Na}^{+}-\mathrm{HCO}_{3}^{-}$cotransporter in mediating cyclic adenosine $3^{\prime}, 5^{\prime}$-monophosphate-dependent $\mathrm{HCO}_{3}^{-}$secretion by mouse endometrial epithelium. Biology of Reproduction 66 1846-1852. (doi:10. 1095/biolreprod66.6.1846)

Wang XF, Zhou CX, Shi QX, Yuan YY, Yu MK, Ajonuma LC, Ho LS, Lo PS, Tsang LL, Liu Y et al. 2003 Involvement of CFTR in uterine bicarbonate secretion and the fertilizing capacity of sperm. Nature Cell Biology $\mathbf{5}$ 902-906. (doi:10.1038/ncb1047)

Received 12 April 2010

First decision 10 May 2010

Revised manuscript received 22 September 2010

Accepted 28 September 2010 